Rev. Saude puibl., S. Paulo

$9: 259-62,1975$

\title{
OBSERVAÇÃO DO COMPORTAMENTO BIOLÓGICO DE BIOMPHALARIA GLABRATA DE CONCHA ANÔMALA
}

SouzA, C.P. de - Observação do comportamento biológico de Biomphalaria glabrata de concha anômala. Rev. Saúde públ., S. Paulo, 9:259-62, 1975.

RESUMO: Foi encontrado na criação de Biomphalaria glabrata em laboratório, um caramujo vivo com anomalia na concha. A anomália consiste na mudança de nivel das voltas. O exemplar foi isolado para estudo de seu comportamento biológico. Depois foi juntado a outro exemplar com a mesma anomalia. Os resultados mostraram que suas funções biológicas eram normais. $A$ anomalia é de caráter genético. $N a F_{1}$ houve aparecimento de $0,01 \%$ de anomalia nos embriões. Em vinte e cinco meses de observação dos descendentes desses caramujos foram isolados treze embrióes anômalos. Um dos embrióes chegou ao estado adulto, mas não desovou.

Unitermos: Biomphalaria glabrata (Anomalias). Planorbidae. Comportamento genético. Esquistossomose.

\section{N T R O DU C Ã O}

0 aparecimento de planobídeos do gênero Biomphalaria com anomalias nas conchas, devido a mudança de nível das voltas, foi observado por Scott ${ }^{3}$, em Tropicorbis peregrinus $(=$ Biomphalaria peregrina) e por Milward de Andrade e Carvalho ${ }^{1}$, em Biomphalaria straminea.

Em nosso laboratório, foi encontrado um exemplar vivo de Biomphalaria glabrata (Say, 1818), com concha anômala. A anomalia consiste na descida da espiral de enrolamento ao longo do eixo, formando uma concha helicoidal ao invés de discoidal, como no molusco normal.

\section{MATERIAL E MÉTODOS}

O caramujo de concha anômala foi encontrado em um aquário de criação de
Biomphalaria glabrata de uma cepa proveniente do Laboratório do Dr. Pellegrino *. Essa cepa é originária do bairro denominado Barreiro em Belo Horizonte e se caracteriza por possuir caramujos albinos e malânicos misturados e ser altamente suscetível à infecção por Schistosoma mansoni em Laboratório.

O caramujo foi isolado em um aquário de pirex contendo aproximadamente mil $\mathrm{ml}$ de água desclorada, com terra esterilizada e carbonato de cálcio e como alimentação foi dado alface fresca.

Após seis dias de isolamento apareceu a primeira desova na parede do aquário. Essa desova foi retirada com bastante cuidado, sendo contado o número de ovos que eram 25 e os embrióes eram todos normais. Daí por diante todas as deso-

* Do Centro de Pesquisas "René Rachou" - INERu. FOC - Caixa Postal 1743 - Belo Horizonte, MG - Brasil

* Instituto de Ciências Biomédicas da Universidade Federal de Minas Gerais 
Sotza, C.P. - Observação do comportamento biológico de Buomphalaria glabrata de conchà anomala Rer. Saúle publ., S. Paulo, 9:259-62, 1975.

vas foram retiradas, sendo contados o número de ovos e os tmbriōes èram observados através de lupa. até a eclosão. Após a eclosão. todos os caramujinhos foram colocados em um aquário separado. para criação e posterior ohservação da descendência.

\section{RESLT.TADOS}

Após 37 dias de isolamento. o caramujo anômalo (Fig. l A-B) foi juntado a outro exemplar com a mesma anomalia. da mesma cepa e que foi encontrado no
Laboratório do Dr. Pellegrino. Por esia épora as desovas do caramujo anormal já estavam com um número pequeno dr ovos variando de 1 a 8 por desora. Cinro dias após juntar os dois caramujoanômalos, as desovas coletadas aumentaram em número e tamanho. variando " número de ovos de 6 a 59 por desovia. Depois de três meses que os caramujoestavam juntos, um dos exemplares nurrrell. O) número de desovas e ovo do caramujo sobrevivente tomou a liaixar quase não havento oviposição até ororrel sua morte. após 12 meses de oheerriçāón.

() número total de desovan torom re-

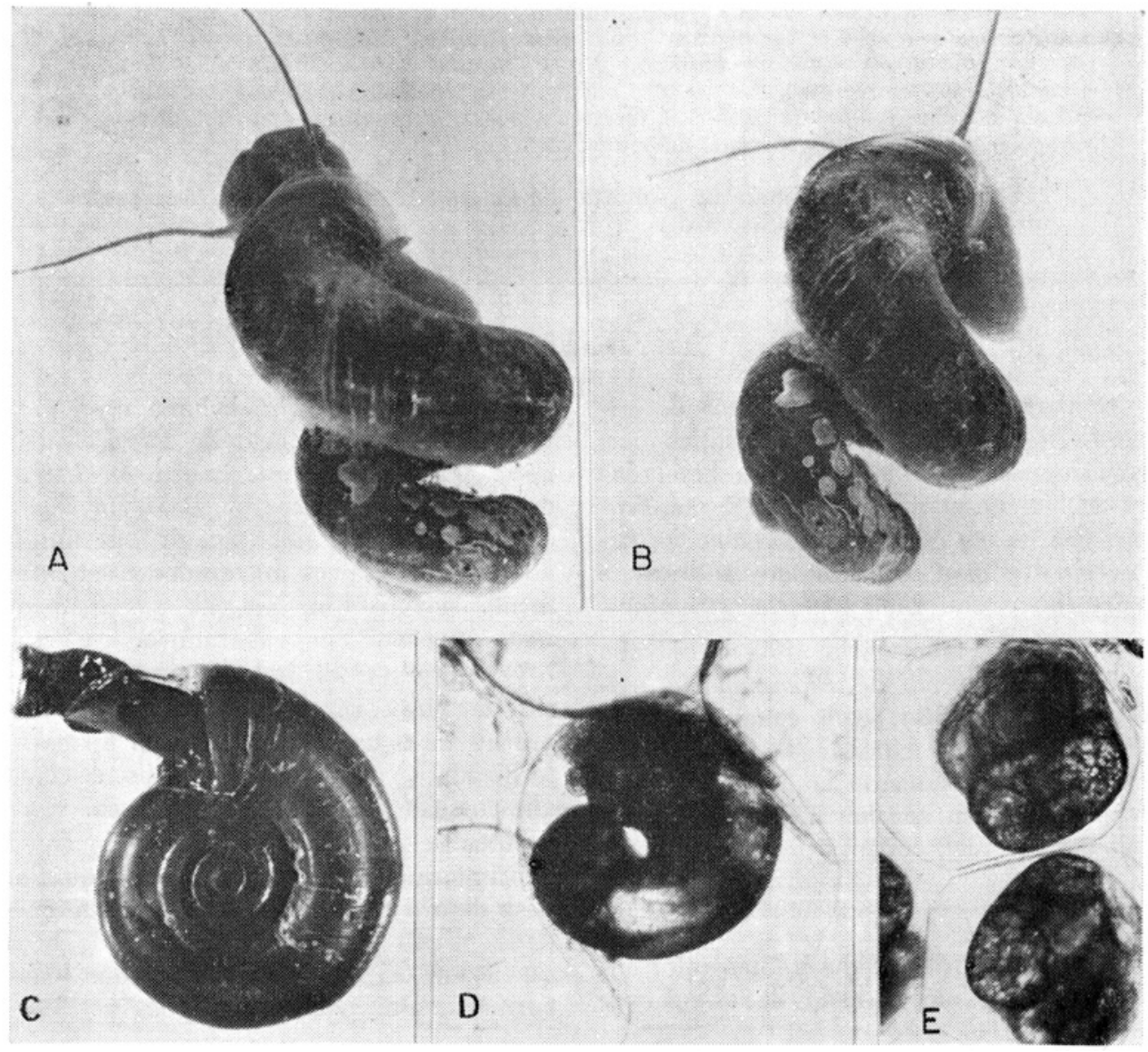

Fig. 1-A e B - Caramujo B. glabrata com concha anômala; C - B. glabrata com conch:: normal: D - Embrião com encha anômala: E - Embriçes com ronchas normais. 
SOLZA, C.P. - Observaçāo do comportamento biológico de Biomphalaria glabrata de concha anomala. Rev. Saude públ., S. Paulo, 9:259-62, 1975.

colhidos dos dois caranmijos anormais, um isolado. e depois os dois juntos e o nú-

mero de embriôes anômalos encontrados podem ser vistos na Tabela 1 .

T A B E L, A 1

Número de desovas, ovos e embriỏes com anomátias, obtidos de dois caramujos $B$. plabrata de concha anômala

\begin{tabular}{|c|c|c|c|c|c|}
\hline $\begin{array}{c}\text { No caramujos } \\
\text { anomalos } \\
\text { aquáro } \\
= \\
\text {. }\end{array}$ & $\begin{array}{l}\text { Tempo } \\
\text { meses }\end{array}$ & $\begin{array}{l}\text { N.o de } \\
\text { desovas }\end{array}$ & So de ovos & $\begin{array}{c}\text { No } \\
\text { embrlóes } \\
\text { anômalos }\end{array}$ & $\begin{array}{l}\text { è } \\
\text { embrióes } \\
\text { Anômalus }\end{array}$ \\
\hline 1 & 9 & 1.97 & 16384 & 1 & 0.06 \\
\hline 2 & 3 & 3866 & $79 \times 2$ & 1) & (1) \\
\hline 2 & 12 & $5 \times 3$ & 9616 & 1 & 0,111 \\
\hline
\end{tabular}

Como pode ser olservado. duranle o período em que os dois caramujos permaneceram juntos. " número de desonas e a múmero de oros por desovas foi hem maior do que os do raramujo isolado.

A percentagem de aparecimento de trmbriões re roniha anômala (Fig. 1-D). na geração $F$ loi de $0.01 \%$.

Ias desovas recolhidas da geraçāo $F$ : em diante foram encontrados doze trmJriões de concha anomala durante vinte e cinco meses de ohiervação.

Apenas três edodiram naluralmente. Seis caramujinhos e'clodiram através da ruptura artificial da membrana do ovo com estilete entomológico. Três embriōes anômalos morreram antes de completar (" desenvolvimento dentro do ovo. Apenas um dos caramujinhos anômalos encontrados sobreviveu até nove meses. Esse raramujo foi mantido isolado da colonia. e não desovou. ao contrário dos exemplares encontrados anteriormente.

Alem da anomalia na concha foram observados rm dois caramujos pequenos. outros tipos de anomalias como hifurcação de um dos tentáculos \& duplicação de um dos olhos ou trinftalmia :

\section{DISCCSA $\operatorname{CO}$}

Alravés dos resultados obtidos rom essas oliservaçôes. verificoul-se que a allomalia oheservada na concha da Biomphalaria glabratu não é devida a ação muànica.

Fila e ds outras malformaçôts olservadas são devidas provavelmente a alyuma mutação senética sofrida por issa cepa de raramujo nāo se sabe se depoique foj trazida para o laboratorio on $\rightarrow$ desder o foco no rampo.

Verificou-se que a anomalia na womeha nāo influiu na biologia do molusco. Dt fato. os caramujos de concha anomala viveram normalmente no meio da rolônia apesar de terem mais dificuldade para locomoveres devido ao enrolamente, helicoidal da concha.

A fase mais reítica da vida dom moluscos com essa anomalia parecell ser a época da eclosăo. ()s emlirióes anomalos não conseguem ste fixar bems à memIrana do ovo e nem forçar a sua ruptura. morrendo a maioria por falta de alimenlo. por ficarem ali por tempo muito prolongado. 
SOUZA, C.P. - Observação do comportamento biológico de Biomphalaria glabrata de concha anómala. Rev. Saúde pübl., S. Paulo, 9:259-62, 1975.

Durante vinte e cinco meses de observação foram isolados treze embrióes com concha anômala, das desovas dos dois caramujos anômalos e seus descendentes. Desses treze caramujinhos, apenas um sobreviveu até chegar ao estado adulto, mas não desovou, provavelmente por ter sido deixado em isolamento.
A GR A DECIMENTOS

Aos Professotes Giorgio Schreiber e José Rabelo de Freitas pelas sugestões e incentivo. Ao Dr. José Pellegrino e ao pessoal de seu laboratório por terem cedido um exemplar anômalo para complementar essas observaçōes.

SouzA, C.P. de - [Observations on the biological behaviour of Biomphalaria glabrata with an anomalous shell]. Rev. Saúde públ., S. Paulo, 9:259-62, 1975 .

SUMmaRy: Among laboratory-bred Biomphalaria glabrata, a live snail in an anomalous shell was found. The anomaly consisted in changes of level in the whorls. The specimen was isolated for a study on its biological behaviour. Afterwards, another specimen displaying a similar anomaly was joined to it. The results obtained showed their biological functions to be normal, their anomaly being of genetic character. In $F_{1}$ embryos, the anomaly observed was $0.01 \%$. In a 25-month period of investigation, 13 anomalous embryos were isolated. One of the embryo snails reached the adult stage but did not lay any eggs.

UNITERMS: Biomphalaria glabrata, Anomalies. Planorbidae. Genetics, behaviour. Schistosomiasis.

\section{REFERENCIAS BIBLIOGRAFICAS}

1. MILWARD DE ANDRADE, R. \& CARVALHO, O.S. - Anomalias em conchas de Biomphalaria straminea (Dunker, 1848), criadas em laboratório (Pulmonata, Planorbidae). Rev. Saúde públ., S. Paulo, 7:283-4, 1973.

2. RAVEN, P.C. - Morphogenesis: the analisis of molluscan development. London, Pergamon Press, 1958.
3. SCOTT, M.I.H. - Um caso de anomalia de forma em Tropicorbis peregrinus (d'Orb) (Planorbidae). Physis, 20: 498-9, 1951.

Recebido para publicacaio em 21-03-1975 Aprovado para publicacio em 04-04-1975 